\section{Microbial carbon pump: additional considerations}

\author{
Chen-Tung Arthur Chen
}

The framework concept of the microbial carbon pump (MCP) and the idea that it stores recalcitrant dissolved organic matter (RDOM) in deep oceans for millennia was first proposed by Jiao et al. (Microbial production of recalcitrant dissolved organic matter: long-term carbon storage in the global ocean. Nature Rev. Microbiol. 8, 593-599 $(2010))^{1}$. This idea has recently received considerable attention $^{2,3}$. However, there are additional considerations that would make it more consistent with the known thermohaline circulation and the distribution of dissolved organic carbon (DOC) in the oceans. Rather than the surface ocean containing only labile DOM (LDOM), it may actually contain more RDOM than LDOM. In addition, known fossil carbon sources in the deep oceans that are unrelated to the MCP increase the apparent age of RDOM. Accordingly, the MCP may not be as effective in storing carbon as originally thought.

The basic idea put forward by Jiao et al. was that any DOM molecules that are not degraded for extended periods effectively store carbon. Jiao et al. classified DOM into three categories based on biological availability — LDOM, semi-labile DOM
(SLDOM) and RDOM. Figures 2 and 4 in their article demonstrate that DOM in the surface layer of the oceans comprises only LDOM, and that SLDOM constitutes most of the DOM that is exported from the euphotic zone to greater depths. Jiao et al. pointed out, correctly, that the mean apparent radiocarbon age of RDOM is high. At $4,000-6,000$ years, it is much higher than the turnover time of oceanic thermohaline circulation ${ }^{4}$. They then claimed that this

"RDOM generation by the MCP might be an important mechanism for the long-term storage of fixed atmospheric carbon by the ocean." (REF. 1)

The RDOM, however, flows with water molecules and completes the thermohaline circulation in approximately 1,000 years. The only way for RDOM to grow to an age of 4,000-6,000 years that does not involve external sources of very old RDOM is for it to turn over four or five times in the water column of the oceans before it is finally decomposed, as discussed later. Therefore, the average RDOM molecule must move to result indicates that: the euphotic layer of the oceans four or five times in its lifetime.

In fact, the minimum apparent ages of DOC in the north-central Pacific and the Sargasso Sea close to surface seawater are at least 3,100 and 2,500 years old, respectively ${ }^{5}$. These values are consistent with the notion that a large fraction of the 4,000-6,000-year-old RDOM moves up to the surface, mainly in the Southern Ocean (FIG. 1). The DOC concentration at the surface of most oceans is in the order of $75 \mu \mathrm{M}$, contrasting with $40 \mu \mathrm{M}$ at depth ${ }^{6}$. The deep-water RDOM seems to survive the trip to the euphotic layer, and this RDOM accounts for more than $75 \%$ of the DOC concentration of $<60 \mu \mathrm{M}$ in the surface layer of the Southern Ocean. North of $50^{\circ} \mathrm{S}$, the surface water DOC levels slowly grow to about $75 \mu \mathrm{M}$, with the increase occurring mainly in LDOM and SLDOM. Restated, the LDOM can only reach a concentration of $35 \mu \mathrm{M}$ of carbon, instead of $75 \mu \mathrm{M}$ of carbon, in the surface layer. Suppose that the 4,000-6,000-year-old RDOM mixes with the newly formed LDOM and SLDOM in the euphotic layer; the apparent age would then be 2,100-3,200 years, which is consistent with the observed ages. Briefly, RDOM should have occupied slightly more than half of the surface layer in figures 2 and 4 of the original article ${ }^{1}$. Accordingly, RDOM must represent more than half of the DOM that is exported from the euphotic zone. Hence, the contribution of SLDOM proposed by Jiao et al. must be reduced by a factor of more than two.

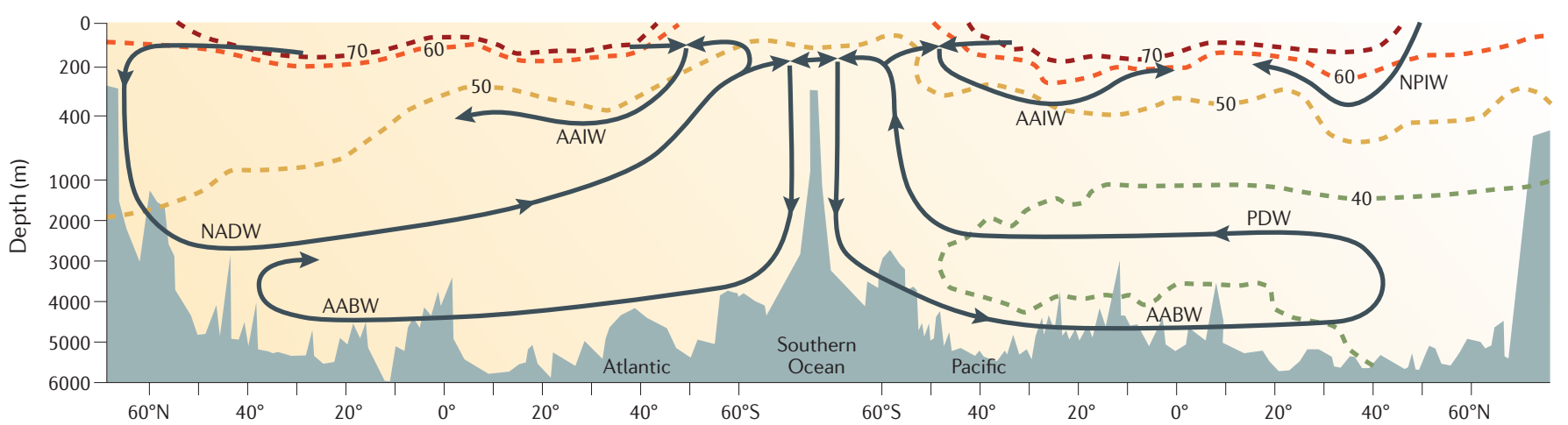

Figure 1 | Schematic diagram of subsurface circulation and DOC distribution in the Atlantic and Pacific Oceans. North Atlantic Deep Water (NADW) sinks and flows southward while the dissolved organic carbon (DOC) concentration decreases from above $60 \mu \mathrm{M}$ to $50 \mu \mathrm{M}$ or below along the way. The NADW upwells in the Southern Ocean. Some of the upwelled water flows northwards and contributes to the Antarctic Intermediate Water (AAIW), which continues to flow northwards. Some of the upwelled NADW sinks back down along the Antarctic continental slope and becomes the Antarctic Bottom Water (AABW). The AABW has a DOC concentration of between $40 \mu \mathrm{M}$ and $50 \mu \mathrm{M}$, and flows eastwards into the Indian and Pacific Oceans. Some of the AABW also flows

northwards in the Atlantic Ocean. The part of the AABW that enters the Pacific flows northwards and then becomes the return flow, which is called the Pacific Deep Water (PDW), now with the lowest DOC concentration - slightly less than $40 \mu \mathrm{M}$. PDW also upwells in the Southern Ocean and contributes to AAIW and AABW. The upwelled NADW and PDW bring around $40 \mu \mathrm{M}$ of carbon in the form of RDOM close to the surface of the Southern Ocean. In the northern Pacific, the North Pacific Intermediate Water (NPIW) also carries a relatively high DOC concentration $(60-70 \mu \mathrm{M})$ to a depth of several hundred metres, and flows southwards. Dashed contour lines indicate DOC concentration $(\mu \mathrm{M})$. Figure is modified from REF. 6. 


\section{CORRESPONDENCE}

However, another issue - which is less certain than the one mentioned above concerns other ways in which the RDOM may appear so old, as none of the three major pathways in the MCP can make the carbon older. Data already show that very old DOC is released in the deep oceans ${ }^{7-10}$ and can make the RDOM appear 1.6-18\% older (see Further information), although the total effect is unknown. Notably, there is an age difference of 2,000 years between the DOC in the deep Pacific Ocean and that in the Atlantic Ocean ${ }^{5}$. As the deep waters flow from the Atlantic to the Pacific in less than 1,000 years, very old DOC is added during the transit and should not be neglected.

Chen-Tung Arthur Chen is at the Institute of Marine Geology and Chemistry, National Sun Yat-Sen University, Kaohsiung 804, Taiwan. e-mail: ctchen@mail.nsysu.edu.tw

doi: 10.1038/nrmicro2386-c4

1. Jiao, N. et al. Microbial production of recalcitrant dissolved organic matter: long-term carbon storage in the global ocean. Nature Rev. Microbiol. 8, 593-599 (2010).

2. Jiao, N., Tang, K., Cai, H. \& Mao, Y. Increasing the microbial carbon sink in the sea by reducing chemical fertilization on the land. Nature Rev. Microbiol 9, 75 (2011).
3. Stone, R. The invisible hand behind a vast carbon reservoir. Science 328, 1476-1477 (2010).

4. Broecker, W. S. \& Peng, T. H. Comparison of Ar-39 and C-14 ages for waters in the deep ocean. Nucl. Instrum. Methods Phys. Res. Sect. B 172, 473-478 (2000).

5. Bauer, J. E., Williams, P. M. \& Druffel, E. R. M. C-14 activity of dissolced organic carbon fractions in the north-central Pacific and Sargasso Sea. Nature 357 , 667-670 (1992)

6. Hansell, D. A., Carlson, C. A., Repeta, D. J. \& Schlitzer, R. Dissolved organic matter in the ocean: New insights stimulated by a controversy. Oceanography 22, 52-61 (2009).

7. Pohlman, J. W. Bauer, J. E., Waite, W. F. Osburn, C. L. \& Chapman, N. R. Methane hydrate-bearing seeps as a source of aged dissolved organic carbon to the oceans. Nature Geosci. 4, 37-41 (2011).

8. McCarthy, M. D. et al. Chemosynthetic origin of C-14-depleted dissolved organic matter in a ridge-flank hydrothermal system. Nature Geosci. 4, 32-36 (2011).

9. Leifer, I., Boles, J. \& Luyendyk, B. Measurement of oil and gas emissions from a marine seep. University of California Energy Institute Technical Report, EDT-009 (Univ. California Berkeley, 2007).

10. Hunt, J. M. Pertoleum Geochemistry and Geology. 617 (W. H. Freeman and Co., San Francisco, 1979).

\section{Acknowledgements}

Discussion with SCOR WG 134 members were most useful. Financial support is provided by the National Science Council of Taiwan and the Aim for the Top University Program of Taiwan.

Competing interests statement

The author declares no competing financial interests.

\section{FURTHER INFORMATION}

Additional information: http://www.mgac.nsysu. edu.tw/ ctchen/Publications/A/nrmicro2386-c4--s1.pdf 